\title{
YAWARweb: Pilot Study about the usage of a Web Service to Raise Awareness of Blood Donation Campaigns on University Campuses in Lima, Peru
}

\author{
Alva Mantari Alicia ${ }^{1}$, Lipa Cueva Alonso ${ }^{2}$, Trinidad Quiñonez Oscar ${ }^{3}$, Brian Meneses-Claudio ${ }^{4}$, \\ Zamora Benavente Isabel ${ }^{5}$, Arias Guzmán Belinda ${ }^{6}$, Delgado-Rivera Gerson ${ }^{7}$, Roman-Gonzalez Avid ${ }^{8}$ \\ Image Processing Research Laboratory (INTI-Lab), Universidad de Ciencias y Humanidades (UCH), Lima, Perú 1, 2, 3, 4, 7,8 \\ Servicio de Hemoterapia y Banco de Sangre, Instituto Nacional de salud del niño San Borja ${ }^{5}$ \\ Banco de Sangre, Hospital Cayetano Heredia $(\mathrm{HCH})$, Lima, Perú ${ }^{6}$
}

\begin{abstract}
This document presents a preliminary study about a pilot deployment of a web service. The service is used as means to raise awareness in university campuses prior to blood donation campaigns and to measure its effect into posterior donor enrollment. The measure the level of awareness a score range from zero to four inclusive was set. It was quantified before and after giving the information. This allowed evaluating the score change influenced by the received information. Another important metric was the contrast between the community participation between the blood donation campaigns at $12^{\text {th }}$ June 2018 and June 2017. During these campaigns 41 and 25 blood units were collected following the new approach and the traditional way respectively. This variation represents an increase of $64 \%$ with respect to the campaign carried out in 2017 by INSN-SB, where the only variation was the use of the application YAWARweb. Moreover, in 2018 there were 36 people interested to donate. Nonetheless, it was not possible because of insufficient hemoglobin, narrow veins, and other causes. This research has as goal to evaluate the usage of our survey through a web service as a tool to raise awareness in university campuses prior to blood donation campaigns. This survey will provide information to the participants about the benefits of blood donation. Thus, creating an incentive to participate in the campaigns and getting the results as an increment of the number of participants. Our group keeps working on preventive health and changing the picture of blood donation leveraged by technology development. The document starts with a general summary of the situation of blood donation in Peru, and then it analyzes the population where the tool is applied. It then proceeds to the methodology of implementation of YAWARweb. Finally, it presents the results of the use of the web application in the community as a method of raising awareness.
\end{abstract}

Keywords-Aplication; survey; blood donation; donor benefits

\section{INTRODUCTION}

Serious patients with leukemia, severe anemia, affected by traumas or women in a critic state before or after giving birth (during pregnancy) need blood units for their treatment and health recovery [1]. That is why blood and its hemo-derivatives are required in health centers to prevent and treat complicated patient's status that may be lethal [2]. World Health Organization (WHO) recomends that $2 \%$ of the population of every country should donate blood in order to have enough supply during a emergency [3]. In Peru, the number of donors is lower than $0.5 \%$ according to the Hemotherapy National Program and Blood Bank (Programa Nacional de Hemoterapia y Bancos de Sangre, Pronahebas). This number becomes even more critical given that only $5 \%$ of it relates to voluntary donations, while $95 \%$ is by blood reposition [4].

Peru needs 600 thousand blood units to have enough supply for an emergency. By 2013185 thousand units were collected. They represent $30.8 \%$ of what is required. In contrast with previous years, the number is increasing, yet it is not close to the target requirement.

This issue arises because donation campaigns do not reach enough people and those that volunteer are scarce. Peru has the lowest index in latinamerica (OPS-2015).

There are 333 Hemotherapy and blood banks in Peru.

There are mobile applications related to blood donation. From those that are present in Googleplay we have analyzed the top 10 with highest ratings finding some common features. In Fig. 1, we show the results of this analysis. They are oriented for donors inscription, sending an alert when they donate, search the nearest donation center, but in general, these applications aim for people that are already aware and are interested in donating blood, none of the applications is aimed at raising awareness. The target audience of our proposed tool YAWARweb are people at university campuses. The tool is anonymous to reduce rejection of participation, provides information about the requirements and personal and altruistic benefits of blood donation.

Our project works on preventive health, through a web service that provides an online survey. The tool is used by people responsible to raise awareness, university students or health personnel. Thus, the process becomes customized and gets a better participation response.

Normally prior to a blood donation campaign an awareness campaign is scheduled. It proposes the use of YAWARweb for the realization of personalized awareness based on the benefits and awareness of blood donation. In Fig. 2, it shows a photo of the awareness campaign with YAWARweb. 


\begin{tabular}{|c|c|c|c|c|c|c|}
\hline Nombre de aplicación & Tamaño & evaluación & $\begin{array}{c}\text { num } \\
\text { personas }\end{array}$ & requerimiento & version & instalaciones \\
\hline dona sangre[Beta] & 9.11 & 3 & 2 & android 4.0.3 & 1.1 .2 & $50+$ \\
\hline Dale Vida Perú & $4.8 \mathrm{M}$ & 4.3 & 9 & android 5.0 & 1.1 .4 & $100+$ \\
\hline Dona Sangre Andalucia & 4 & 3.3 & 175 & android 4.0.3 & 1.0 .2 & $10000+$ \\
\hline Donante & $755 \mathrm{~K}$ & 4.1 & 22 & android 2.3.3 & 2.1 & $500+$ \\
\hline Donan de sangre de Euskadi & 3.7 & 4.2 & 115 & android 4.1 & 1.3 .3 & $5000+$ \\
\hline Dona + & 6.7 & 4.6 & 10 & android 4.4 & 0.0 .6 & $100+$ \\
\hline Donantes & $485 \mathrm{~kb}$ & 1.8 & 4 & android 2.1 & $0.99 \mathrm{~b}$ & $100+$ \\
\hline Anmol blood donor search app & $3.8 \mathrm{M}$ & 0 & 2 & android 4.0.3 & 2 & $100+$ \\
\hline $\begin{array}{l}\text { Blood Friends - blood donate } \\
\text { app }\end{array}$ & $4.2 \mathrm{M}$ & $\mathbf{0}$ & 45 & android 4.1 & 1.0 & $1000+$ \\
\hline
\end{tabular}

Fig. 1. Table of the Characteristics of Applications Similar to YAWARweb.

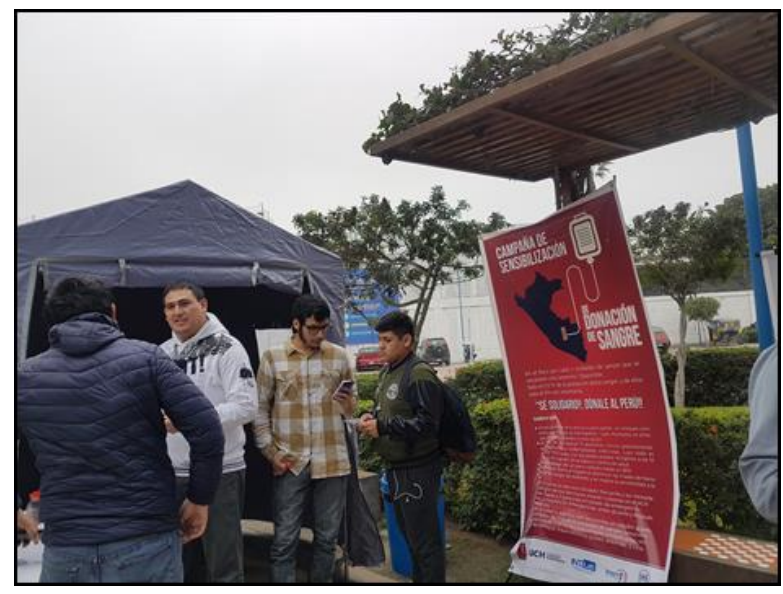

Fig. 2. Photograph of the Awareness Campaign using YAWARapp.

Our web service has been designed in such a way it is specific, sensitive, trustful and useful. This service will enable the assessment of potential blood donors and raise awareness prior to blood donation campaigns in university campuses.

\section{Population AND SAmple}

\section{A. Sample}

Data has been collected opportunistically at the campus of Universidad de Ciencias y Humanidades, by 11th June 2018, from 9:00am to midday. In total 114 people were approached.

It can describe from the approached people that the age range was between 18 to 50 . We have divided this range into three. From 18 to 22,22 to 30 and 30 to 50 representing the $78.07 \%, 9.65 \%$ and $12.28 \%$ of the population respectively. This is shown in the following Table I.

It is also important to analyze the gender distribution. It was $3 \%$ and $27 \%$ for the female and male participants respectively.

It is described in Table II.

TABLE I. AGE RANGE OF PARTICIPANTS

\begin{tabular}{|l|l|l|l|}
\hline \multicolumn{4}{|l|}{ Age range } \\
\hline Total Participants & $\mathbf{1 8 - 2 2}$ & $\mathbf{2 2 - 3 0}$ & $\mathbf{3 0 - 5 0}$ \\
\hline 114 & 89 & 11 & 14 \\
\hline $100 \%$ & $78.07 \%$ & $9.65 \%$ & $12.28 \%$ \\
\hline
\end{tabular}

TABLE II. PARTICIPANTS GENDER TABLE

\begin{tabular}{|l|l|l|}
\hline \multicolumn{2}{|l|}{ Gender of participants } \\
\hline Total Participants & Female & Male \\
\hline 114 & 68 & 46 \\
\hline $100 \%$ & $59.65 \%$ & $40.35 \%$ \\
\hline
\end{tabular}

\section{Methodology}

The developed tool YAWARweb, was done with $\mathrm{php}(\mathrm{v}$ 5.2.19), apache(v 2.4.18) and Mysql (v 5.7.11).

The data base of the web service showed differentiated data identification to 1) determine if the participant is able for donation and 2) provide information about blood donation benefits. The following Fig. 3 describes the structure.

User identification is not enabled for survey participants. This identification is for personnel responsible of the raise of awareness (Fig. 4). The illness table is to identify those illnesses that exclude the participant as donor. Personal information data is optional in case the participant is willing to receive information about being a donor or campaign promoter.

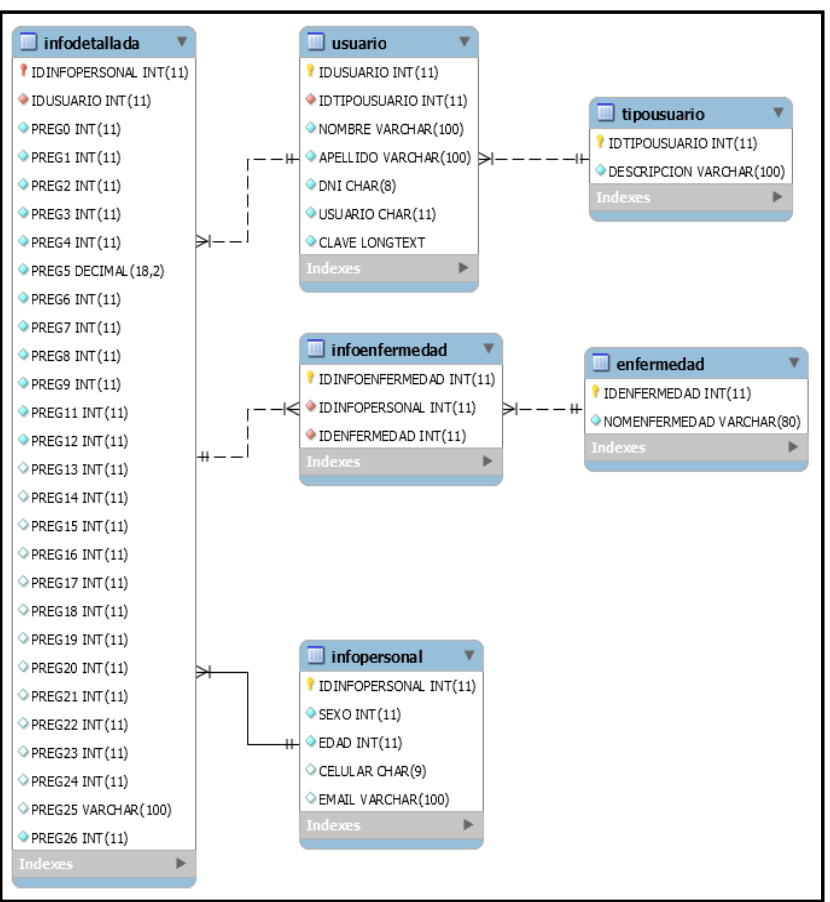

Fig. 3. Structure of the YAWARapp Information Tables.

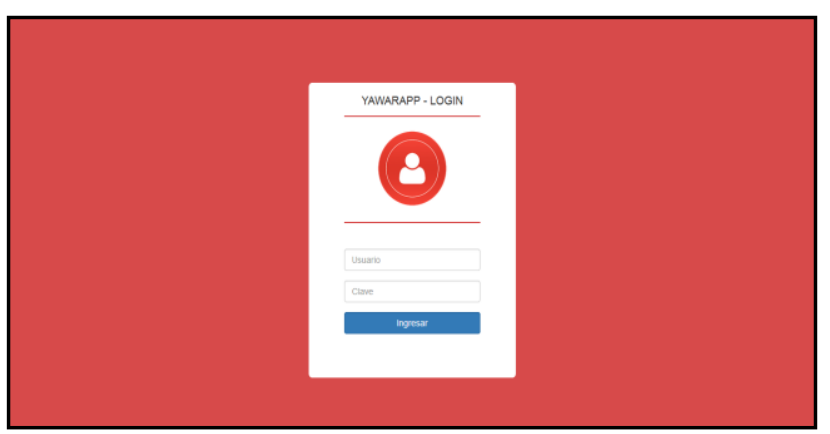

Fig. 4. Initial Web Screen of the YAWARweb Web Application. 
Question groups are:

1) Initial appreciation of blood donation.

2) Questions to evaluate if the participant is able to be a donor.

3) Direct benefits of blood donation.

4) Benefited population by the blood donation.

5) Ask if it the participant wants to receive information about becoming a donor.

6) Lastly, evalute the appreciation of blood donation after acknowledging the benefits of blood donation.

This is a first study about the required data to design YAWAR web. Therefore this analysis is descriptive, explaining key findings and focusing on the overall characteristics from the population of university campuses and their point of view about blood donation. The survey was anonymous. Information collected was divided into three sections: First section- preferences and scoring of 23 statements on the benefits of donating blood; Second sectioneligibility criteria for potential blood donation; Third sectionparticipants' likelihood of donating bloods given the information provided on its benefits.

Questionnaires were disseminated by INTIlab team members to UCH and UPCH students studying nursing, accounting, administration, electrical engineering, biology, physics, and computer science.

The division of sections is detailed as follows:

First Section: Details were provided of 23 potential benefits so that participants could give a score between zero and four where zero is disagree and four is fully agree. In addition, every potential benefit was given in both a statement and a question from. Participants were asked to pick which format they preferred or alternatively they could reject the benefit altogether, it can display the home screen of the web application in Fig. 5.

The aforementioned benefits included examples of benefits for either the donor or the recipient of blood. Below are some examples of the benefits of blood donation that are given in the questionnaire:

- Serves a general health check.

- Thirteen blood analyses are undertaken on a sample of your blood for free [3].

- Reduces the number of cardiac arrests [4].

- Reduces blood viscosity [5].

- Reduces the amount of iron in blood.

- Rejuvenates the body [5].

- Benefits for regular blood donors.

- The amount of people that can be helped [3].

- Patient groups that benefit.

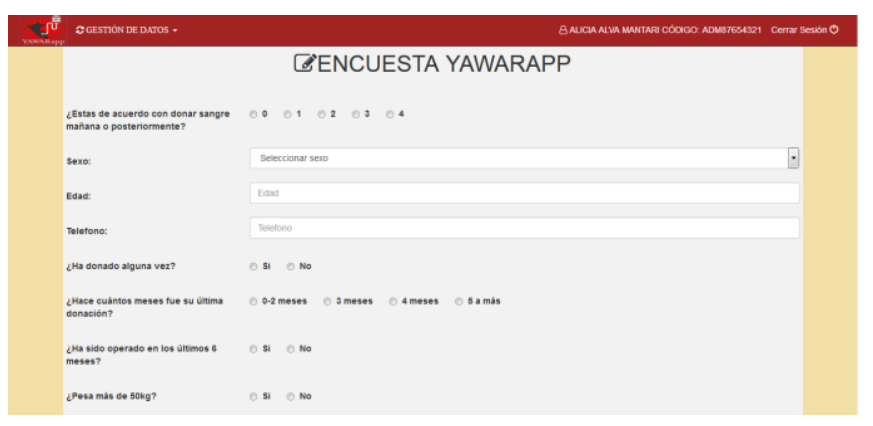

Fig. 5. Representation of Oblique TEC (sTEC) and Vertical TEC (vTEC).

Second Section: Twelve questions are asked relating to the individuals health and prior illnesses to help establish if they may be eligible for blood donation. These questions were based on the pre-donation forms used by Hospital Cayetano Heredia's blood bank, San Borja International Clinic, and the Peruvian Institute of Child Health.

Third section: At the beginning of the questionnaire participants are asked to score their willingness to donate blood and why they have chosen that score. In the third section at the end of the questionnaire this same question is asked again. This is done in order to evaluate if the information given on the potential benefits of blood donation have changed the participants willingness to donate. We have used this measure to initially evaluate if a tool such as YAWARweb that explains the benefits of blood donation could indeed improve blood donation rates on university campuses prior to donation campaigns. In addition, the third section has questions on participants' opinions on receiving text messages containing information on the benefits of blood donation.

The service used the university services and the Image Processing INTI-Lab Laboratory server.

The service also allows to see the received data in real time.

\section{RESULTS AND CONCLUSIONS}

The questionnaire was designed in order to facilitate the collection of information regarding the public's opinions on blood donation. The goal is that this could be used as a tool for raising awareness prior to blood donation campaigns on university campuses. The amount of valid particiants for this study was 114 .

The knowledge about the benefits of blood donation was evaluated. The following statements on the benefits of donation received the highest scores:

- Thirteen blood analyses are undertaken on a sample of your blood for free.

- Reduces the number of cardiac arrests [6].

- Reduces hepatic damages [7].

- Benefits as regular donors.

- Reduces diabetes risks [8].

- Patient groups that benefit. 


\begin{tabular}{|l|l|l|}
\hline Benefit & Frequency & Percentage \\
\hline $\begin{array}{l}\text { Donation as check-up, } \\
\text { perform a blood count }\end{array}$ & 51 & 44.74 \\
\hline $\begin{array}{l}\text { Additional exams } \\
\text { approximate cost \$ 150 }\end{array}$ & 12 & 10.53 \\
\hline $\begin{array}{l}\text { Reduces the likelihood of } \\
\text { heart attack }\end{array}$ & 13 & 11.4 \\
\hline $\begin{array}{l}\text { Decreases damage to the } \\
\text { liver }\end{array}$ & 17 & 14.91 \\
\hline Decreases risk of diabetes & 17 & 14.91 \\
\hline $\begin{array}{l}\text { Twice a year to be a } \\
\text { frequent donor }\end{array}$ & 11 & 9.65 \\
\hline $\begin{array}{l}\text { Blood is divided into blood } \\
\text { products }\end{array}$ & 40 & 35.09 \\
\hline $\begin{array}{l}\text { of every 4 units needed } \\
\text { there is only one available }\end{array}$ & 25 & 21.93 \\
\hline Benefits pregnant women & 34 & 29.82 \\
\hline Oncology patients & 43 & 37.72 \\
\hline Surgery & 51 & 44.74 \\
\hline
\end{tabular}

Fig. 6. List of Benefits and Knowledge of each unop in the Participating Population.

We can observe in Fig. 6 that the less known statement, with only $9.65 \%$ of acknowledgement, is becoming a regular donor. Hence, by doning it is possible to receive blood analysis results within 10 to 15 days. These exams have a cost of USD 150.00 in private clinic laboratories in Peru. By donating the exams are free.

In the second questionaire group, about the willingness to become a donor, $83.33 \%$ of the participants have never donated blood. It is shown in the following Table III.

The last date of donation was also asked, it was found that only 2 from those that have previously donated have done it in the last 5 months before the survey (Table IV). This disable them to donate in the next campaign.

Among the participants, $51.75 \%$ and $48.25 \%$ were qualified as potential donors and disqualified respectively, as you can see in Fig. 7.

TABLE III. PREVIOUS DONOR PARTICIPATION TABLE

\begin{tabular}{|c|c|c|}
\hline \multicolumn{3}{|l|}{ Previous donor } \\
\hline Total Participants & Donated before & Never donated \\
\hline 114 & 19 & 95 \\
\hline $100 \%$ & $16.67 \%$ & $83.33 \%$ \\
\hline
\end{tabular}

TABLE IV. LAST DONATION TABLE

\begin{tabular}{|c|c|c|}
\hline \multicolumn{3}{|l|}{ Previous donor } \\
\hline Total Participants & $\begin{array}{l}\text { Donation before } 5 \\
\text { months }\end{array}$ & $\begin{array}{l}\text { Donation in more } \\
\text { than } 5 \text { months }\end{array}$ \\
\hline 114 & 2 & 112 \\
\hline $100 \%$ & $1.75 \%$ & $98.25 \%$ \\
\hline
\end{tabular}

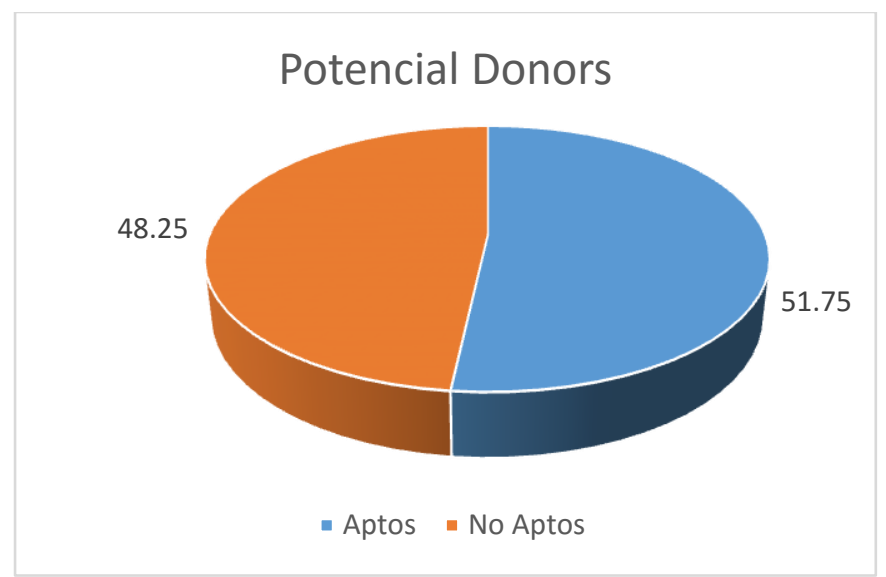

Fig. 7. Graph of the Number of Participants Eligible for Blood Donation whom Participated in the Awareness Campaign.

The third group of questions measures if acknowledging the donation benefits influenced the willingness to donate. The results show that $61.40 \%, 35.09 \%$ and $3.51 \%$ kept, raised and diminished their appreciation, respectively; this can be seen in Fig. 8 and Table V.

This is the first metric for the YAWARweb tool in benefit for raise awareness of participant prior to blood donation campaigns. Another metric to evaluate the efficiency of the campaign is to measure if the participation rate improved significantly. Therefore we have the following chart:

TABLE V. AWARENESS ANALYSIS

\begin{tabular}{|l|l|l|l|}
\hline \multicolumn{4}{|l|}{ Valorization of blood donation } \\
\hline $\begin{array}{l}\text { Total } \\
\text { Participants }\end{array}$ & $\begin{array}{l}\text { Kept their } \\
\text { valorization }\end{array}$ & $\begin{array}{l}\text { Raised their } \\
\text { valorization }\end{array}$ & $\begin{array}{l}\text { Diminished their } \\
\text { valorization }\end{array}$ \\
\hline 114 & 70 & 40 & 4 \\
\hline $100 \%$ & $61.40 \%$ & $35.09 \%$ & $3.51 \%$ \\
\hline
\end{tabular}

\section{Chart Ared/alorization of blood donation}

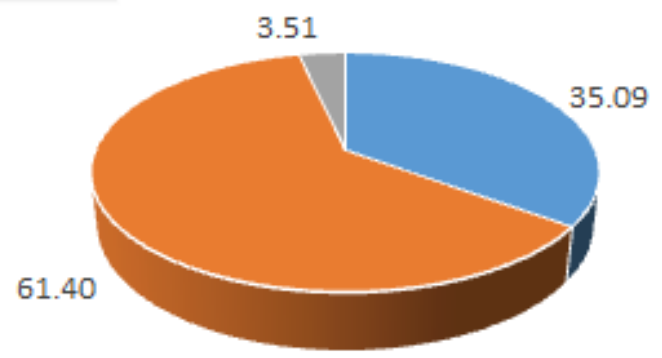

\section{Raised their valorization - Diminished} Kept their valorization

Fig. 8. Percentage of Participants who Increased their Assessment Since Yawarweb. 


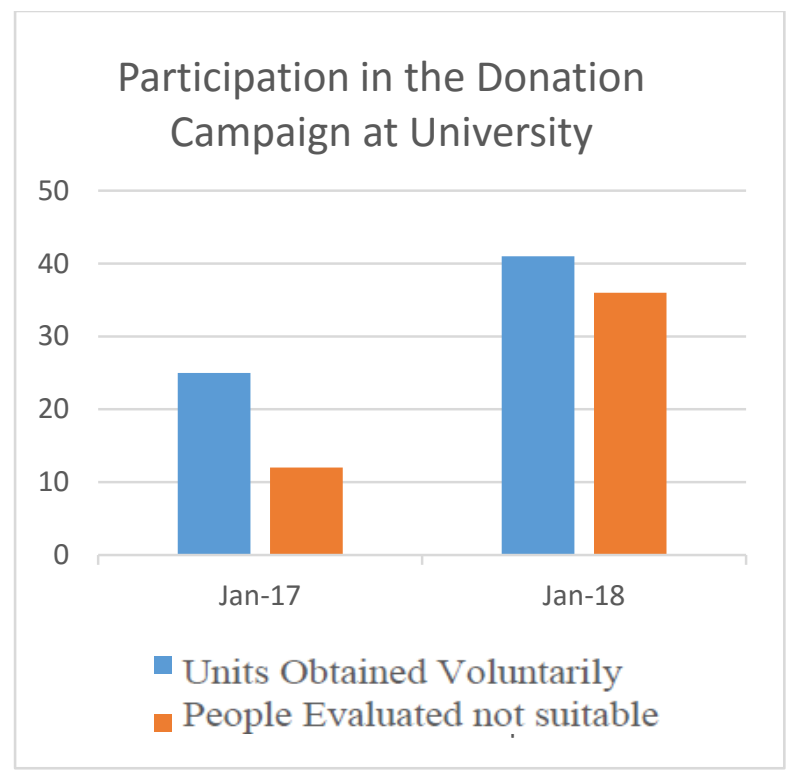

Fig. 9. Variation of Participation in the Blood Donation Campaign, Yawarweb was used in the Awareness Campaign in 2018.

In Fig. 9, it can visualize the effect of using YAWARweb as part of the awareness campaign, where a $64 \%$ increase has been found in comparison with a previous campaign. In addition, 40 people that received the intervention, one day before the campaign of June $12^{\text {th }}$, arrived with a great interest of participation.

As a consequence of the analysis of the pilot usage of the web service as part of a prior awareness stage before a blood campaign we can conclude:

1) With YAWARweb, the knowledge of people from the university campuses about the benefits and destination of blood donation was evaluated. This measurement was performed as described in Table III.

2) The most known statement in the survey was relate to the initial hemogram in a donation procedure. It was known by the $44.74 \%$ of the participants. The least known statement was about the role of a regular donor that provides the Blood Bank from Cayetano Heredia Hospital. It was ignored by $90.35 \%$ of the participants. Moreover, the benefits as renewal of the blood torrent as a result of the donation was also ignored. It was surprising that $64.91 \%$ of the participants ignored that blood was divided into hemo-components and as consequence one person was not benefit but three. Because blood is divided into red blood cells, plasma and platelets. Also considering the fact that the blood sample goes under 13 tests at least.

3) The following Table VI shows how many people did not know the benefits present on each statement.

4) Participants are more likely to participate in this kind of awareness campaign because it is customized. Most of them had questions about the information that was provided and their interest to keep receiving information to become a donor or donation promoter. This fact is remarkable. The amount of participants willing to receive information are shown in the following Table VII.
TABLE VI. AMOUNT OF KNOWLEDGE OF THE BENEFITS

\begin{tabular}{|l|l|l|}
\hline Benefit & $\begin{array}{l}\text { People that } \\
\text { did not know }\end{array}$ & Percentage \\
\hline $\begin{array}{l}\text { Donation as a health check, hemogram } \\
\text { analysis. }\end{array}$ & 63 & 55.26 \\
\hline $\begin{array}{l}\text { Additional tests valued on USD 150 } \\
\text { approximately }\end{array}$ & 102 & 89.47 \\
\hline Reduces risks of a heart attack & 101 & 88.60 \\
\hline Reduces liver damages & 97 & 85.09 \\
\hline Reduces diabetes risk & 97 & 85.09 \\
\hline $\begin{array}{l}\text { If donates twice a year becomes } \\
\text { regular donor }\end{array}$ & 103 & 90.35 \\
\hline $\begin{array}{l}\text { Blood is devided into three } \\
\text { components (Hemo-derivatives) }\end{array}$ & 74 & 64.91 \\
\hline $\begin{array}{l}\text { Only one of 4 required units is } \\
\text { available }\end{array}$ & 89 & 78.07 \\
\hline Benefits pregnant women & 80 & 70.18 \\
\hline Benefits oncological patients & 71 & 62.28 \\
\hline $\begin{array}{l}\text { Benefits patients of surgery, traumas, } \\
\text { anemias, etc }\end{array}$ & 63 & 55 \\
\hline
\end{tabular}

TABLE VII. PEOPLE INTERESTED IN PARTICIPATE

\begin{tabular}{|l|l|l|}
\hline Condition & Frequency & Percentage \\
\hline Donor & 53 & 46.49 \\
\hline Promoter & 13 & 11.40 \\
\hline Not interested & 12 & 10.53 \\
\hline Donor and Promoter & 25 & 21.93 \\
\hline Left empty & 11 & 9.65 \\
\hline TOTAL & $\mathbf{1 1 4}$ & $\mathbf{1 0 0}$ \\
\hline
\end{tabular}

From the participants, $46.49 \%, 11.40 \%, 21.93 \%$ and $~ 20 \%$ were interested in receiving information to become a donor, promoter, donor and promoter and not interested or left empty this section, respectively. Those interested in becoming a promoter were aware they require additional training.

5) The raise of awareness one day before a campaign is effective. There was a significant increment of $64 \%$ of participation during this blood donation campaign performed by the UC of INSNSB.

6) It is important to provide options to people interested in donation but unabled to do it. An example is to encourage the rol of promoters.

7) The training to the support personnel was done in one hour. Solving doubts and teaching them how to use the online service. The service has been shown to be usable and easy to use by people interested in the process.

The objective of this study was to use all the described items in order to demonstrate that the usage of this tool to raise awareness on the topic of blood donation is valid and thus, increase the participation rates.

The obtained results will facilitate the next phase of our study with a better understanding of the target population from university campuses. 
An asynchronous application will be implemented in a next stage of research, in order to massify the use of YAWARweb by the blood banks of Lima, as part of the awareness campaigns, this will allow an increase in participation in donation campaigns, through a free and simple tool.

The advantages of using YAWARweb is the reproducibility of the information delivered properly concentrated and prepared by specialists at low cost, the fact of having correct information allows to reduce the barriers in the population for blood donation, the delivery of personalized information supports to the awareness of the university students in the requirements to the population that is benefited with their donation, the registration of the data and the synchronization of the same for epidemiological analysis that will allow a detailed study of the population in which the Blood donation campaigns, and massification, will allow us to carry out more rigorous analyzes of diseases by communities, risk behaviors, or predisposition for promoters or potential donors.

We would like to thank UCH for their support in the development of the questionnaires and for providing financial support to the initial phase of this proof of concept of the project YAWARweb. In addition, we would also like to thank the Blood Bank for the information they have provided us and guidance to use the questionnaire as a tool for increase awareness in population prior to blood donation campaigns on university campuses. Finally, thank the Blood Bank of the Instituto Nacional de Salud del Niño de San Borja for allowing us to use the tool in the blood donation campaign as an alternative tool to raise awareness.

We keep working on preventive health and to diminish health gaps all over our country.

\section{REFERENCES}

[1] F. Velasquez Vázquez, C. A. Caicedo, and C. A. Tabares, "SALVE UNA VIDA: 'DONE SANGRE,"” Estud. Gerenciales, vol. 20, no. 91, pp. 91-114, Jun. 2004.

[2] A. Valdés et al., "Estructura y funcionamiento de los bancos de sangre en 4 provincias cubanas," Rev. Cuba. Hematol. Inmunol. Hemoter., vol. 20, no. 1, pp. 0-0, Apr. 2004.

[3] T. W. Gillespie and C. D. Hillyer, "Blood donors and factors impacting the blood donation decision," Transfus. Med. Rev., vol. 16, no. 2, pp. 115-130, Apr. 2002.

[4] R. Salcedo, J. Fuentes, and O. Roca Valencia, "La experiencia de Perú con un programa nacional de bancos de sangre," Rev. Panam. Salud Pública, vol. 13, pp. 165-171, Mar. 2003.

[5] J. Morales, J. Fuentes-Rivera, C. Delgado-Silva, and H. Matta-Solís, "[Viral Hepatitis Infection Markers Among Blood Donor in a National Hospital of Metropolitan Lima]," Rev. Peru. Med. Exp. Salud Publica, vol. 34, no. 3, pp. 466-471, Sep. 2017.

[6] J. T. Salonen, T. P. Tuomainen, R. Salonen, T. A. Lakka, and K. Nyyssönen, "Donation of blood is associated with reduced risk of myocardial infarction. The Kuopio Ischaemic Heart Disease Risk Factor Study," Am. J. Epidemiol., vol. 148, no. 5, pp. 445-451, Sep. 1998.

[7] J. C. Barton, A. J. Grindon, N. H. Barton, and L. F. Bertoli, "Hemochromatosis probands as blood donors," Transfusion (Paris), vol. 39 , no. 6 , pp. 578-585.

[8] H. van Jaarsveld and G. F. Pool, "Beneficial effects of blood donation on high density lipoprotein concentration and the oxidative potential of low density lipoprotein," Atherosclerosis, vol. 161, no. 2, pp. 395-402, Apr. 2002. 